\title{
Sintering Trials of Analogues of Americium Oxides for Radioisotope Power Systems
}

\author{
E. J. Watkinson ${ }^{1 a}{ }^{*}$, R. M. Ambrosi ${ }^{1 a}$, D. P. Kramer ${ }^{2}$, H. R. Williams ${ }^{16}$, M. J. Reece ${ }^{3}$, K. Chen ${ }^{3}$, M. J. \\ Sarsfield ${ }^{4}$, C. D. Barklay ${ }^{2}$, H. Fenwick ${ }^{4}$, D. P. Weston ${ }^{1 b}$ and K. Stephenson ${ }^{5}$. \\ ${ }^{1 a}$ Department of Physics and Astronomy and ${ }^{1 b}$ Department of Engineering, University of Leicester, \\ Leicester, LE1 7RH, UK. \\ ${ }^{2}$ University of Dayton Research Institute, Kettering Laboratories, 300 College Park, Dayton $\mathrm{OH}$ \\ 45469-0172, USA. \\ ${ }^{3}$ Queen Mary University of London, School of Engineering and Materials Science, Mile End Rd, \\ London, E1 4NS, UK. \\ ${ }^{4}$ National Nuclear Laboratory, Central Laboratory, Sellafield, Seascale, Cumbria, CA20 1PG, UK. \\ ${ }^{5}$ European Space Agency, ESTEC, Noordwijk, The Netherlands. \\ * Corresponding author: Tel. +44 (0) 116223 1033. E-mail: ejw36@le.ac.uk
}

\begin{abstract}
European Space Agency radioisotope power systems will use americium oxide as the heat source in pellet or disc form. The oxide form is yet to be decided. Sintering trials with $\mathrm{CeO}_{2}$ and $\mathrm{Nd}_{2} \mathrm{O}_{3}$ as analogues for $\mathrm{AmO}_{2}$ and $\mathrm{Am}_{2} \mathrm{O}_{3}$ were conducted. Spark plasma sintering (SPS) and cold-press-andsinter methods were compared. Different sintering parameters and particle characteristics were investigated with commercial and synthesised powders. The synthesised powders contained lathshaped particles and batches with different particle sizes and specific surface areas were made and sintered. This is the first study in the public literature to report the sintering of lath-shaped $\mathrm{CeO}_{2}$.

The targeted density range of $85-90 \%$ was met using both techniques. No ball-milling was required. Cold-pressing-and-sintering $\mathrm{CeO}_{2}$ produced intact discs. Large cracking was prevalent in the SPS discs. Some powders pressed more successfully than others. Powder morphology had a significant effect on the result but it was not possible to fully quantify the effects in this study. The cold-pressed-andsintered $\mathrm{CeO}_{2}$ discs had comparable Vickers hardness values to a nuclear ceramic $\left(\mathrm{UO}_{2}\right)$. The hardness values were greater than the spark plasma sintered $\mathrm{CeO}_{2}$ sample. Efforts to SPS near-net shaped pellets using $\mathrm{CeO}_{2}$ and $\mathrm{Nd}_{2} \mathrm{O}_{3}$ are reported. A follow on investigation was conducted to assess how the $85-90 \%$ T.D. target could be achieved. The aspect ratio impacts the sintering parameters and behaviour. The Vickers hardness of $\mathrm{Nd}_{2} \mathrm{O}_{3}$ is reported for the first time and compared to the results of sintered $\mathrm{CeO}_{2}$.
\end{abstract}

\section{Introduction}

Radioisotope power systems (RPS) enable deep space exploration as well as the ability to probe some of the more challenging environments on the surfaces of solar system bodies. Unlike solar power systems, RPSs are independent of the local solar intensity. The versatility of radioisotope thermoelectric generators (RTGs) and radioisotope heater units (RHUs) has enabled a range of space missions since the 1960s that would not have been possible with solar power [1-3].

The European Space Agency (ESA) started a research and development programme in 2008 to develop a European RPS [4-7]. Americium-241 $\left({ }^{241} \mathrm{Am}\right)$ was identified as a viable and affordable fuel for Europe [4]. It was selected as the radioisotope fuel despite its reduced specific thermal power compared to ${ }^{238} \mathrm{Pu}[8]$. The ESA programme has since progressed to the production and processing 
of americium oxide, and the development of different RPS technologies including RTGs [5], RHUs and Stirling generators [4].

Different forms of americium oxide are being investigated to select a preferred fuel form. These include oxides ranging from $\mathrm{Am}_{2} \mathrm{O}_{3}$ to $\mathrm{AmO}_{2}$. The material will need to be in a form that can be integrated easily into an RPS system. Historically, the RPS systems built by the United States have used consolidated $\mathrm{PuO}_{2}$ with various geometries including spheres, discs and pellets [1].

The overarching aim of this study was to investigate and demonstrate the sintering of suitable surrogate oxides for americium oxides whilst comparing the performance of the cold-press-andsinter and spark plasma sintering (SPS) approaches. The requirement was for a reproducible process to produce an intact cylindrical pellet of $\sim 13 \mathrm{~mm}$ diameter by $\sim 16 \mathrm{~mm}$ long. It was sized assuming a requirement for an RHU generating several watts of thermal power $\left(\sim 3 W_{\text {th }}\right)$. Two main driving constraints were considered. Firstly that the relative density of the material should be $85-90 \%$ of theoretical density to allow helium escape during operation. Secondly, for radiological protection reasons, the powder used for the sintering should not be subject to any ball-milling prior to sintering. This is both to reduce respirable fines and equipment contamination [9].

In conventional cold-press-and-sinter, powders are compacted under pressure (typically by using a steel die) at room temperature to improve their packing density to form 'green' bodies [10]. The green discs or pellets are then heated in a furnace according to a specified time-temperature cycle to sinter the compact. The sintering dwell time for cold-pressed-and-sintered bodies can be several hours. In spark plasma sintering, the heat is generated by direct Joule heating of conductive dies and the powder if it is sufficiently electrically conductive. This allows high sintered densities to be achieved much more quickly and/or at lower temperatures than conventional methods. It also has the potential to manufacture near-net shaped pellets [11]. Graphite dies are often used and so SPS is described as providing a reducing sintering environment for sintering oxides [12]; this is a potential disadvantage compared to the conventional cold-press-and-sinter approach.

Non-radioactive surrogate materials provide early insights into how the fuel will behave without the challenges of working with active material [13]. Neodymium (III) oxide $\left(\mathrm{Nd}_{2} \mathrm{O}_{3}\right)$, cerium (IV) oxide $\left(\mathrm{CeO}_{2}\right)$ and solid solution oxides of the two have been identified as appropriate surrogates for $\mathrm{Am}_{2} \mathrm{O}_{3}, \mathrm{AmO}_{2}$ and sub-stoichiometric $\mathrm{AmO}_{2}$, respectively, based on crystal phases and cationic radii, and on transition temperatures, melting points and thermal expansion coefficients [7, 13, 14]. The current ESA americium fuel chemical flow-sheet creates $\mathrm{AmO}_{2}$ particles with lath-shaped morphology of tens of micrometres in size [15]. Production of surrogate $\mathrm{CeO}_{2}$ material using a directly analogous oxalate precipitation and calcination process has also been demonstrated to produce micrometric lath-shaped $\mathrm{CeO}_{2}$ particles [16].

Cold-press-and-sinter has been successfully demonstrated for nanometric $\mathrm{CeO}_{2}$ powders [17-22]. Near full density was achieved in a number of these studies. Reduction of the ceria, resulting in oxygen outgassing, pore production and reduced relative densities of between $70-85 \%$ was observed in some studies $[17,18,23]$. Wang [19] demonstrated the cold-press-and-sinter of $\mathrm{CeO}_{2}$ at a larger powder size of $5 \mu \mathrm{m}$; however, this was ball-milled before sintering. Roleček et al. [24] reported a comparison of cold-press-and-sintered milled and non-milled powder. The relative densities achieved were $72.2 \%$ to $91.3 \%$ when non-milled powder was used, and $81.4 \%$ to $95.4 \%$ when milled powder was used. Data for particle size and morphology of the powder (in particular whether the powder is lath-shaped) were not reported by Roleček et al. [24]. Cold-press-and-sinter of $\mathrm{Nd}_{2} \mathrm{O}_{3}$ has been reported [25] using powder with an average grain size of $4 \mu \mathrm{m}$, achieving a relative density of $86-89 \%$ but with cracking attributed to a hygroscopic reaction. 
There has been limited research into the SPS of pure or doped $\mathrm{CeO}_{2}$. Choi et al. $[26,27]$ investigated the SPS processing of pure nanometric $\mathrm{CeO}_{2}$ and achieved greater than $97 \%$ relative density. Roleček et al. [24] reported a comparative study on the SPS and cold-press-and-sinter of $\mathrm{CeO}_{2}$. SPS allowed a much reduced processing time ( $5 \mathrm{~min} c f 1$ hour) and pressure (50 MPa cf $300 \mathrm{MPa})$; however, there was XRD evidence of reduction to $\mathrm{Ce}_{2} \mathrm{O}_{3}$. Mori et al. [28] also reported difficulties in the densification of doped nano- $\mathrm{CeO}_{2}$ processed using SPS due to reduction. The SPS of ball-milled $\mathrm{Nd}_{2} \mathrm{O}_{3}$ powder, which had a nominal particle of size of $4 \mu \mathrm{m}$ prior to milling, was demonstrated to achieve high relative density of $98.8 \%$ [7].

One of the few mechanical properties reported for actinide oxides and their surrogates is Vickers hardness $[7,29,30]$. This standard technique can be conducted on small samples of material [31], and the data obtained allow an initial comparison with collated values of similar materials. Jahromi [22] measured the Vickers hardness of cold-press-and-sintered $\mathrm{CeO}_{2}$ using a $0.25 \mathrm{~N}$ testing load to be between $4.6 \mathrm{GPa}$ and $7.7 \mathrm{GPa}$ depending on sintering temperature. No open literature reporting Vickers hardness for pure $\mathrm{Nd}_{2} \mathrm{O}_{3}$ has been found.

The objective of this study was therefore to investigate spark plasma sintering (SPS) and conventional cold-pressing-and-sintering of micrometric $\mathrm{CeO}_{2}$ and $\mathrm{Nd}_{2} \mathrm{O}_{3}$. Wherever practical, these studies would use lath-shaped micrometric $\mathrm{CeO}_{2}$ produced directly from the wet chemical process that would be applicable to the eventual flight fuel form. In all cases, ball-milling of the powders would be avoided. The study is exploratory with no known public studies on the SPS of such large particulate $\mathrm{CeO}_{2}$ or on the effect of the lath particle morphology on sintering behaviour.

The development of an SPS process using commercially available micrometric $\mathrm{CeO}_{2}$ sintered in two stages to manage the reduction and outgassing is reported. These sintering parameters were then used to produce near-net shaped ceria pellets using lath-shaped material. Pellets were also produced using conventional cold-press-and-sinter from lath-shaped material of different particle sizes and specific surface areas. Finally, the SPS of commercially available $\mathrm{Nd}_{2} \mathrm{O}_{3}$ was performed to demonstrate the production of near-net shape pellets and for Vickers hardness measurement.

\section{Method}

\subsection{Materials}

Pale yellow commercial $\mathrm{CeO}_{2}$ powder ( $99.9 \%$ purity, Sigma Aldrich, UK) with a particle size $<5 \mu \mathrm{m}$ was procured for use in the initial SPS studies. This approach was taken because the wet chemical process for synthesising $\mathrm{CeO}_{2}$ produces small volumes of material and more material was needed for initial trials. The as-received particles are shown in Figure $1 \mathrm{a}$.

Wet-chemically synthesised $\mathrm{CeO}_{2}$ was prepared via an oxalate precipitation and calcination process. The former used $0.083 \mathrm{M}$ cerium (III) nitrate hexahydrate in $0.2 \mathrm{M}$ nitric acid and $0.68 \mathrm{M}$ oxalic acid. The method is a continuous precipitation process [16] and is similar to a process previously described [13]. The oxalate precipitation temperature and calcination temperatures used are given in Table 1. This process yields lath-shaped particles as shown in Figure 1b. A Malvern Mastersizer 3000 was used to conduct the particle size analysis using a wet dispersion technique. It used low angle laser light scattering to obtain particle size distributions. A Micrometrics Tristar2 was used to measure the SSA of the powder samples using the Brunauer-Emmett-Teller (BET) method. Table 1 shows that the calcination temperature has a significant effect on specific surface area, with a lower calcination temperature resulting in a higher specific surface area. The impact of the precipitation and calcination conditions on particle size was more subtle as shown by Table 1. 
Commercially sourced neodymium(III) oxide powder ( $99.9 \%$ purity, Alfa Aesar, UK) was procured for the SPS trials using the same product code as stated in a previous SPS study, which had a particle size of approximately $4 \mu \mathrm{m}[7]$.

Table 1: Outlines the wet-chemical synthesis oxalate precipitation and calcination conditions used to make the different batches of lath-shaped $\mathrm{CeO}_{2}$, together with their sizes and specific surface areas.

\begin{tabular}{|c|c|c|c|c|c|c|c|}
\hline \multirow[t]{2}{*}{ Batch \# } & \multirow{2}{*}{$\begin{array}{l}\text { Oxalate } \\
\text { Precipitation } \\
\text { Temp. }\left({ }^{\circ} \mathrm{C}\right)\end{array}$} & \multirow{2}{*}{$\begin{array}{l}\text { Calcination } \\
\text { Temp. }\left({ }^{\circ} \mathrm{C}\right)\end{array}$} & \multicolumn{4}{|c|}{ Particle Size $(\mu \mathrm{m})$} & \multirow{2}{*}{$\begin{array}{l}\text { Specific Surface Area } \\
\qquad\left(\mathrm{m}^{2} \mathrm{~g}^{-1}\right)\end{array}$} \\
\hline & & & $d_{10}$ & $d_{50}$ & $d_{90}$ & $\begin{array}{l}\text { Volume } \\
\text { Mean }\end{array}$ & \\
\hline 1 & 25 & 500 & 5 & 25 & 68 & 32 & 67 \\
\hline 2 & 25 & 650 & 6 & 27 & 70 & 33 & 20 \\
\hline 3 & 25 & 900 & 6 & 27 & 73 & 38 & 2 \\
\hline 4 & 60 & 500 & 5 & 23 & 78 & 33 & 69 \\
\hline 5 & 60 & 650 & 4 & 13 & 37 & 17 & 17 \\
\hline 6 & 60 & 900 & 5 & 20 & 62 & 28 & 4 \\
\hline
\end{tabular}
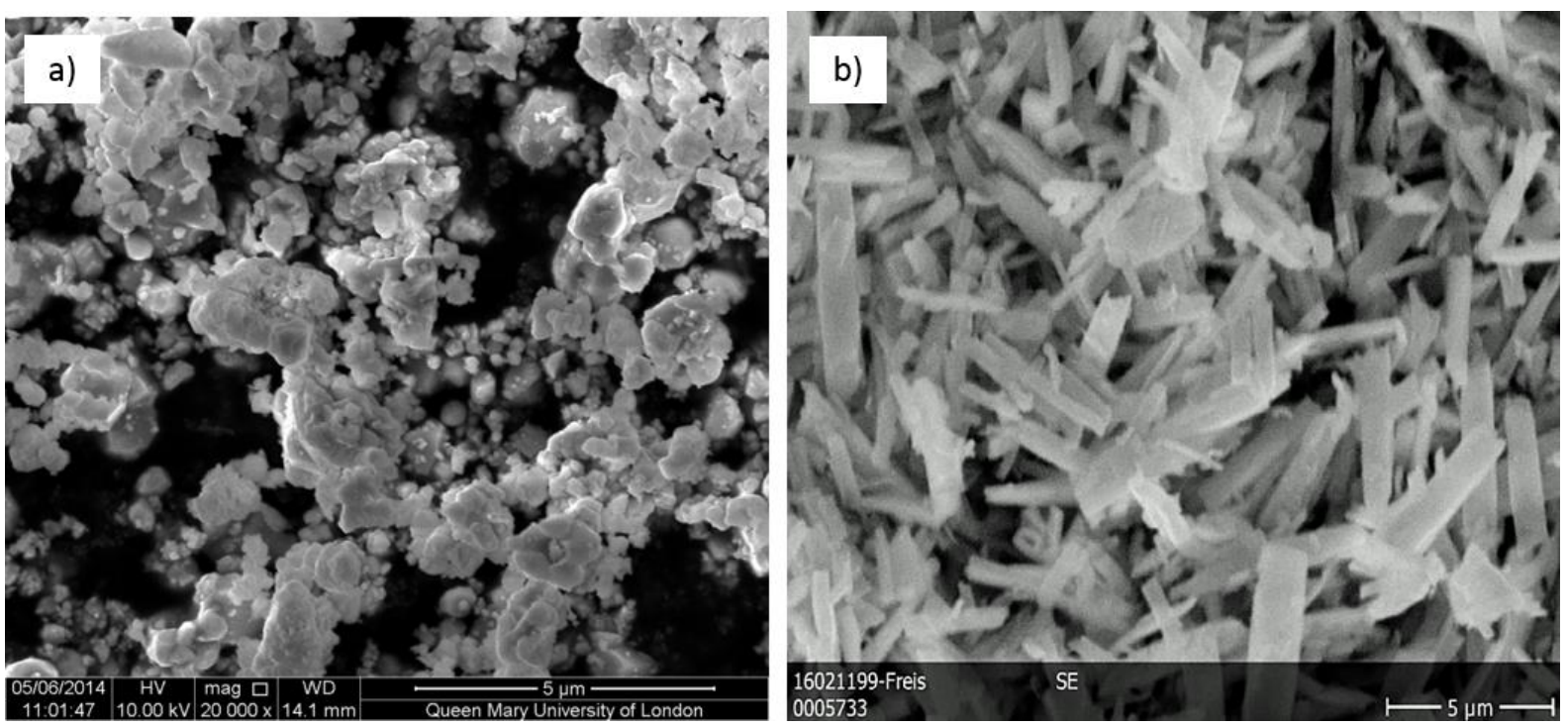

Figure 1: SEM images of (a) the as received $\mathrm{CeO}_{2}$ commercial material and (b) an example of synthesised lathshaped $\mathrm{CeO}_{2}$.

\subsection{Sintering Profiles and Methodology}

\subsubsection{Spark Plasma Sintering of Cerium (IV) Oxide}

Initial trials investigated the heating rate, peak temperature, pressure, hold time and the cooling conditions for producing $20 \mathrm{~mm}$ diameter disc specimens using a single step sintering profile. The main parameters investigated were the variation of temperature between $1100{ }^{\circ} \mathrm{C}$ and $1500{ }^{\circ} \mathrm{C}$ and pressures of $50 \mathrm{MPa}$ and $80 \mathrm{MPa}$. The pressure of gas evolved from the specimen during processing 
was measured by the SPS furnace. A graphite die (Duragraph 20) was used with graphite paper (Papyex N998) to aid electrical contact.

Sintering profiles $A$ and $B$, which are illustrated in Figure 2 , were used to sinter $20 \mathrm{~mm}$ diameter discs ( $A$ and $B$ ) using commercial $\mathrm{CeO}_{2}$ powder. The first sintering stage in each profile targeted 1050 ${ }^{\circ} \mathrm{C}$ and $1100{ }^{\circ} \mathrm{C}$, respectively, to allow the material to reduce and lose oxygen at a lower relative density. The higher temperatures and pressures of the second stage of each profile were used to consolidate the reduced ceria. The discs were allowed to free cool.

The wet-chemically synthesised lath-shaped $\mathrm{CeO}_{2}$ from batches 1 and 2 were sintered using sintering profile $\mathrm{C}$, which is illustrated in Figure 2, to target the fabrication of cylindrical near-net shaped pellets. A graphite die (Duragraph 465) with an internal diameter of $13 \mathrm{~mm}$ was used with a target pellet length of $16 \mathrm{~mm}$. The sintering profile was based on Condition B but featured a more gradual cooling profile $\left(20^{\circ} \mathrm{C} \mathrm{min}^{-1}\right.$ from $1300^{\circ} \mathrm{C}$ to $450^{\circ} \mathrm{C}$ and then to room temperature with no pressure applied) and a lower pressure of $50 \mathrm{MPa}$. These changes were made with the aim of reducing the risks of failure of the graphite die and pellet cracking due to thermal stresses. 

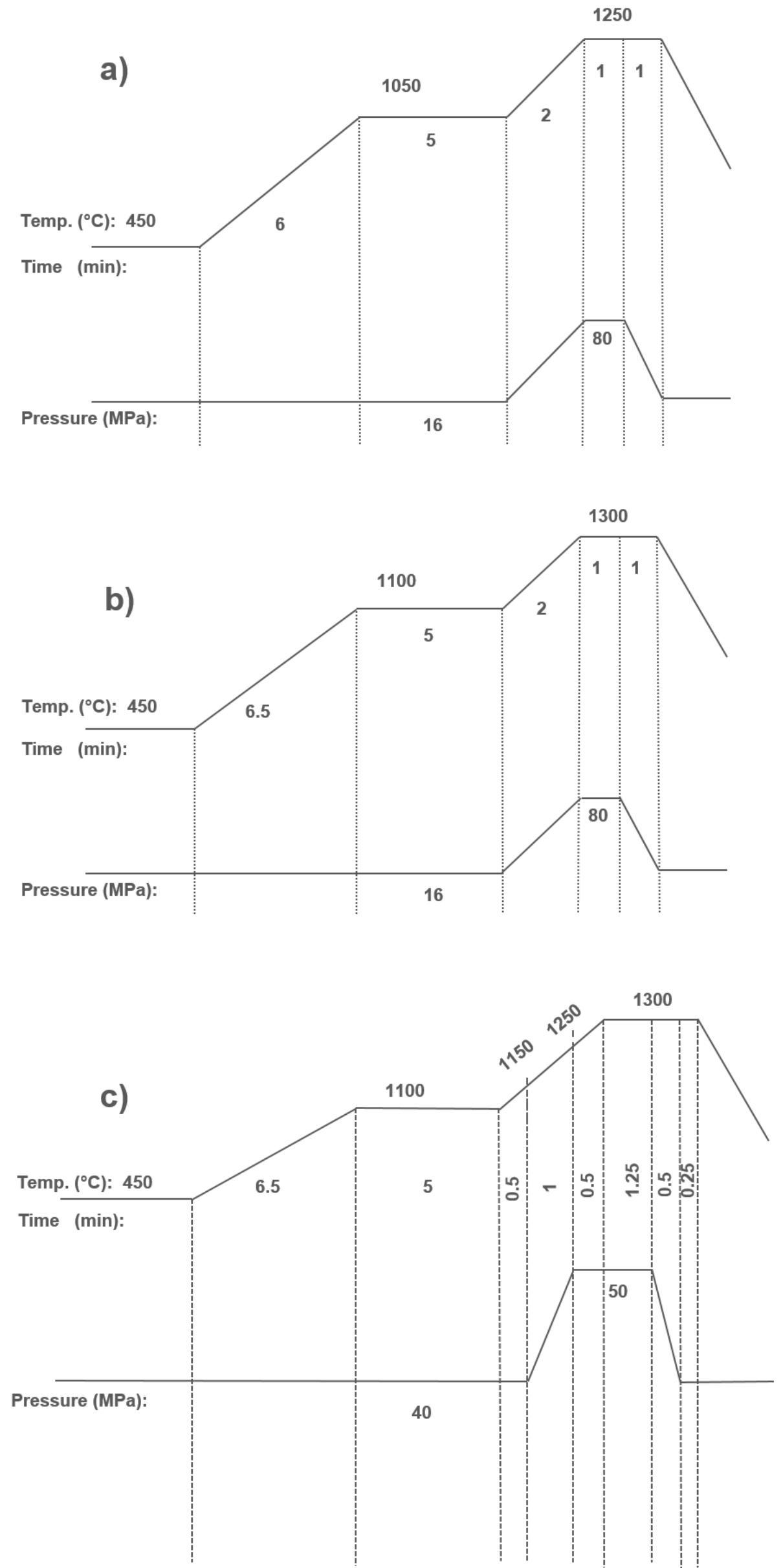
Figure 2: SPS Sinter profiles. a) Two-stage SPS Condition A used with commercial $\mathrm{CeO}_{2}$; b) Two-stage SPS Condition $\mathrm{B}$ used with commercial $\mathrm{CeO}_{2}$ and c) Two-stage SPS Condition $\mathrm{C}$ used with lath-shaped $\mathrm{CeO}_{2}$ and commercial $\mathrm{Nd}_{2} \mathrm{O}_{3}$ to produce near-net shape pellets.

\subsubsection{Cold-Press-and-Sinter of Cerium (IV) Oxide}

Wet chemically synthesised lath-shaped $\mathrm{CeO}_{2}$ from batches 1-6 (see Table 1) were pressed into discs using a $53 \mathrm{kN}$ load and a die with inner dimension of $8 \mathrm{~mm}$. No binder was used. It was not possible to produce intact green discs out of $\mathrm{CeO}_{2}$ batches 4 and 6 . Multiple attempts were made with batch 4. A programmable furnace with $\mathrm{MoSi}_{2}$ u-pin elements (CM Inc., Bloomfield, NJ) was used to sinter the green bodies. The sintering profile used is shown schematically in Figure 3.

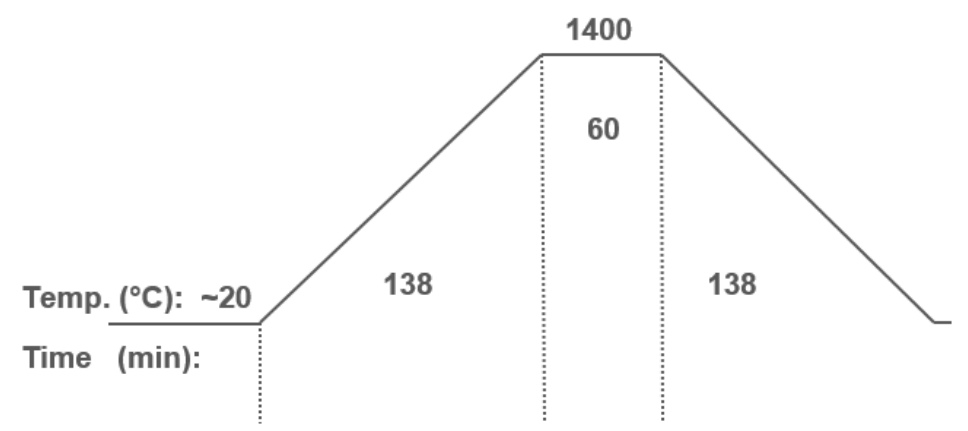

Figure 3: The sintering profile used to sinter the cold pressed lath-shaped $\mathrm{CeO}_{2}$ discs in air.

\subsubsection{Spark Plasma Sintering of Neodymium (III) Oxide}

Sintering profile Condition $\mathrm{C}$, which is depicted in Figure 2, was used to demonstrate whether a near-net shaped pellet could be fabricated from commercially procured $\mathrm{Nd}_{2} \mathrm{O}_{3}$. Sample dimensions were the same as those for the $\mathrm{CeO}_{2}$ pellets (section 2.2.1). Condition $\mathrm{C}$ was adapted by varying the temperature between $1000{ }^{\circ} \mathrm{C}$ and $1350{ }^{\circ} \mathrm{C}$, whilst keeping the pressure at $50 \mathrm{MPa}$, to identify a suitable temperature to achieve the target relative density of $85-90 \%$. A further near-net shape pellet was then sintered using the temperature identified by this part of the study to investigate the effect of the aspect ratio on the sintering behaviour.

\subsection{Characterisation}

The relative density of the discs was calculated geometrically, rather than using an Archimedes method, in order to prevent potential degradation of the specimens due to immersion in any liquid. All $\mathrm{CeO}_{2}$ materials were nominally assumed to have a theoretical density of $7.20 \mathrm{~g} \mathrm{~cm}^{-3}$. The theoretical density of $\mathrm{Nd}_{2} \mathrm{O}_{3}$ was taken to be $7.24 \mathrm{~g} \mathrm{~cm}^{-3}$. A combined uncertainty estimate on the relative density was produced for all specimens based on measurement precision. Specimens were stored in sealed vacuum bags in a dry cabinet for between one week and nine months between production, inspection and testing.

Microscope and visual inspection of the specimens was performed to investigate the microstructure and to confirm whether intact pellets could be produced for each material and sintering condition.

Vickers hardness tests were used to assess the mechanical properties of materials produced since this is one of the few mechanical parameters for which literature data for actinide and lanthanide oxides were available. Measurements were performed following ASTM standard C1327-08 [31] using 
a $300 \mathrm{~g}$ load and $15 \mathrm{~s}$ dwell time on ground and polished specimens cold mounted in epoxy resin at ambient conditions. Ten acceptable indents were used to calculate a mean and standard deviation of the hardness for each test case. The $\mathrm{CeO}_{2}$ spark plasma sintered discs were mounted such that their fractured surfaces would be polished. The near-net shaped SPS pellet, cold-pressed-andsintered $\mathrm{CeO}_{2}$ discs and an $\mathrm{Nd}_{2} \mathrm{O}_{3}$ disc produced using SPS were mounted with their circular faces upwards. Vickers hardness tests were performed at two different institutions and by different operators. This meant they were potentially susceptible to subjective differences such as in judging acceptability of indentation morphology and minor differences in procedures such as repeat measurements of individual indentations. For example, scanning electron microscopy (SEM) was used to measure the indents in the $\mathrm{CeO}_{2}$ SPS discs because material uplift made it difficult to obtain focussed optical images. These factors should be considered when comparing the results. However, in this case the objective is to generate indicative data only and so any procedural difference does not place major limitations on the study conclusions.

\section{Results}

\subsection{Cerium (IV) Oxide}

\subsubsection{Behaviour of $\mathrm{CeO}_{2}$ under Spark Plasma Sintering}

The results of the one-stage initial SPS sintering trials using commercially sourced $\mathrm{CeO}_{2}(\S 2.2 .1)$ are shown in Table 2. The discs cracked on removal from the die. Visual observation of the discs revealed they were generally grey rather than pale yellow, which was the colour of the powder prior to sintering.

The results in Table 2 show that a small change in parameters can have a large effect on the relative density of the disc. Achieving the required relative density range of $85-90 \%$ can be readily achieved by selecting the appropriate conditions. Figure 4 illustrates the fractured surfaces of some of the produced discs. It qualitatively illustrates that an increase in temperature improved consolidation. The impact of increasing the temperature from $1200^{\circ} \mathrm{C}$ to $1300^{\circ} \mathrm{C}$ under an $80 \mathrm{MPa}$ pressure for 3 min resulted in grain growth. Increasing the sintering temperature to $1500^{\circ} \mathrm{C}$ resulted in a significant change in fracture surface microstructure. This is illustrated in Figure 5 , which is at a higher magnification than Figure 4. The sintering is improved in the $1500^{\circ} \mathrm{C}$ disc; however, its angular surfaces suggest grain pull-out and non-optimal consolidation. Figure 6 shows that outgassing was detected in one of the early trial discs as the temperature passed $1025^{\circ} \mathrm{C}$. 
Table 2: The parameters used for single-stage SPS using commercially sourced $\mathrm{CeO}_{2}$.

\begin{tabular}{lllllllll}
\hline $\begin{array}{l}\text { Temperature } \\
\left({ }^{\circ} \mathrm{C}\right)\end{array}$ & $\begin{array}{l}\text { Pressure } \\
(\mathrm{MPa})\end{array}$ & $\begin{array}{l}\text { Time } \\
(\mathbf{m i n})\end{array}$ & $\begin{array}{l}\text { Mass } \\
(\mathbf{g})\end{array}$ & $\begin{array}{l}\text { Diameter } \\
(\mathbf{m m})\end{array}$ & $\begin{array}{l}\text { Thickness } \\
(\mathrm{mm})\end{array}$ & $\begin{array}{l}\text { Sintered } \\
\text { Density } \\
\left(\mathbf{g ~ c m}^{-3}\right)\end{array}$ & $\begin{array}{l}\% \\
\text { Theoretical } \\
\text { Density } \\
(\text { T.D. })\end{array}$ & $\begin{array}{l}\text { SPS Machine } \\
\text { Left to Free } \\
\text { Cool at high } \\
\text { temperature? } \\
\text { (Yes/No) }\end{array}$ \\
\hline 1100 & 50 & 3 & 7.2 & 20 & 4.3 & 5.3 & $74 \pm 1.4$ & No \\
1250 & 50 & 3 & 7.2 & 20 & 3.8 & 6.0 & $84 \pm 1.7$ & Yes \\
1200 & 80 & 0 & 7.2 & 20 & 4.5 & 5.1 & $71 \pm 1.3$ & No \\
1200 & 80 & 3 & 7.2 & 20 & 3.9 & 5.9 & $82 \pm 1.6$ & No \\
1300 & 80 & 3 & 7.2 & 20 & 3.6 & 6.4 & $88 \pm 1.9$ & No \\
1500 & 80 & 3 & 7.2 & 20 & 3.5 & 6.5 & $91 \pm 2.0$ & No \\
\hline
\end{tabular}
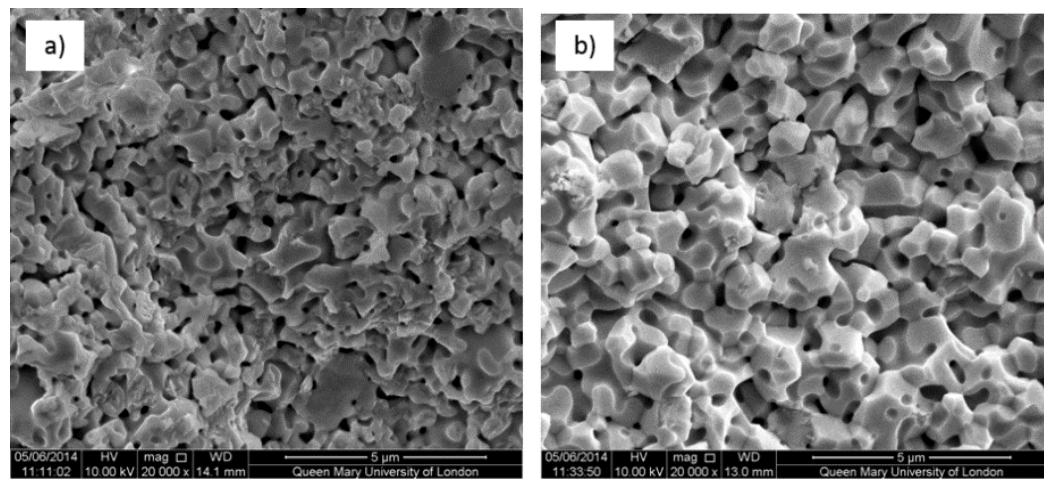

Figure 4: The microstructures ( $5 \mu \mathrm{m}$ scale) of some of the single-stage SPS ceria made under the following conditions: a) $1200{ }^{\circ} \mathrm{C} / 80 \mathrm{MPa} / 3 \mathrm{~min}$ and b) $1300{ }^{\circ} \mathrm{C} / 80 \mathrm{MPa} / 3$ min using commercial $\mathrm{CeO}_{2}$.

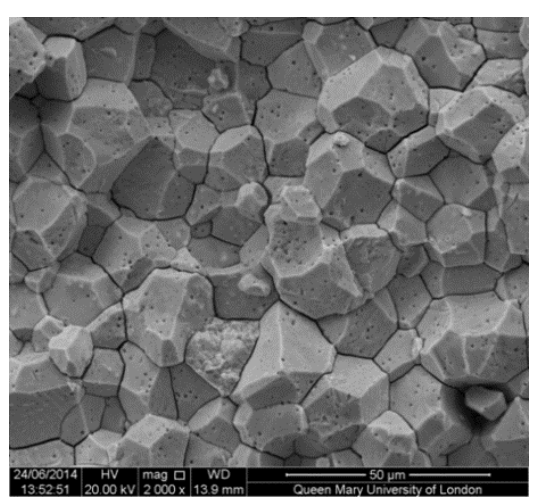

Figure 5: The microstructure of a single-stage SPS disc made at $1500{ }^{\circ} \mathrm{C} / 80 \mathrm{MPa} / 3 \mathrm{~min}$ using commercial $\mathrm{CeO}_{2}$. 


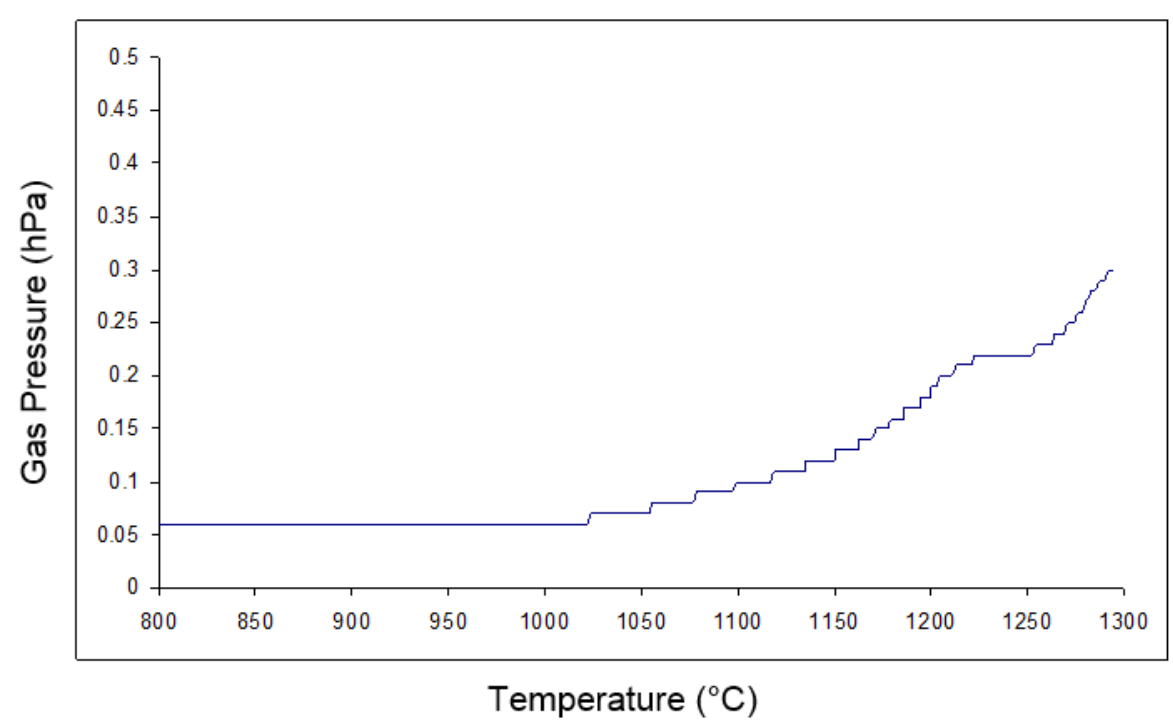

Figure 6: Outgassing from the SPS Chamber.

The objective of using a two-stage SPS process with commercially sourced $\mathrm{CeO}_{2}$ was to allow the material to outgas and reduce at a lower temperature and pressure and then to allow the ceria to sinter at a higher temperature and pressure in order to mitigate the cracking observed in the specimens manufactured in a single stage. The fractured surfaces of the two-stage SPS $\operatorname{discs} A$ and B (made under conditions $A$ and $B$ shown in Figure $2 a$ and $2 b$, respectively), which were manufactured using commercial $\mathrm{CeO}_{2}$, are illustrated in Figure 7. Disc $\mathrm{A}$ was intact and disc $\mathrm{B}$ was broken on removal from the die. A small change in sintering profile from condition $A$ to $B$ resulted in a large change in relative density and microstructure: discs $A$ and $B$ had relative densities of $79 \pm 1.2 \%$ and $88 \pm 1.4 \%$, respectively, and disc $B$ evidenced improved sintering when compared to disc A. Disc $B$ also had small pores. The ground and polished fragments of disc $A$ and disc $B$ are shown in Figure 8 . Disc $A$ had a central lighter region and a darker border. It was not clear whether there was an evolution over time in the colour, and therefore in the oxygen to metal ratio, of this central region during the several months between when the disc was made, stored, and then ground and polished for analysis. To aid seeing this colour difference effect, the image contrast and brightness of the top left corner of the sample has been increased in Figure 8. The central region appeared porous as it readily absorbed the coloured polishing fluid. The mounted and polished disc $B$ is also shown in Figure 8. It was much darker and did not show a colour gradient. Figure 8 also illustrates SEM images of the two polished discs. There was a clear difference in grain size and disc B evidenced grain pullout. 
A)
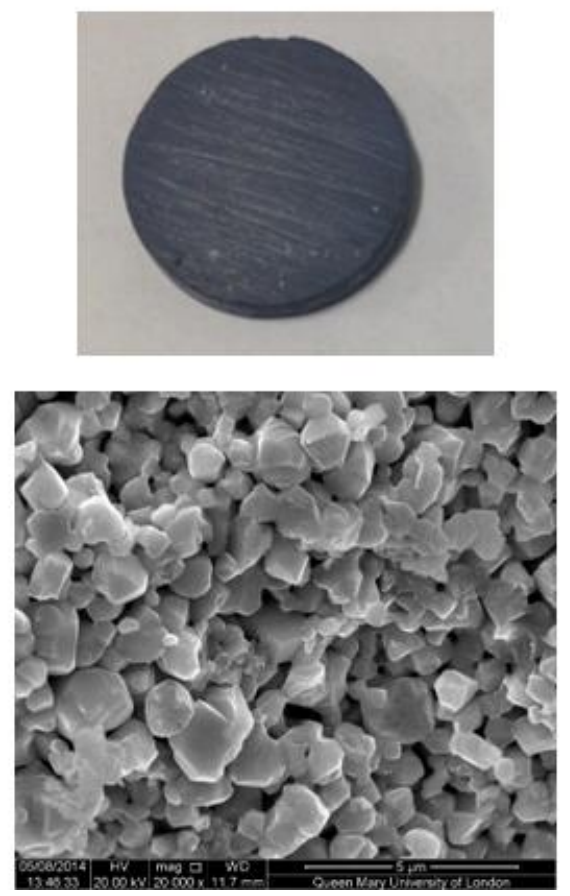

B)
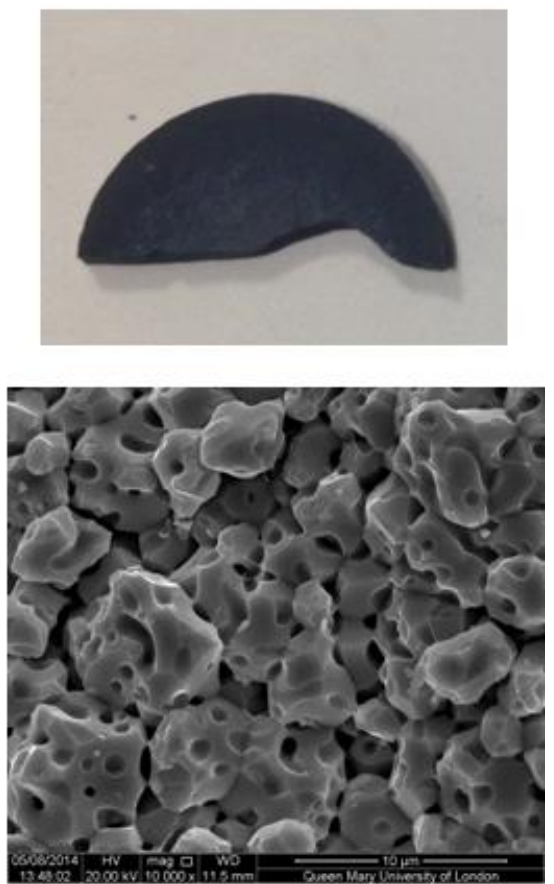

Figure 7: A) the fractured surfaces of A) disc A made by SPS Condition A and B) disc B made by SPS condition $B$ using commercial $\mathrm{CeO}_{2}$.

A)
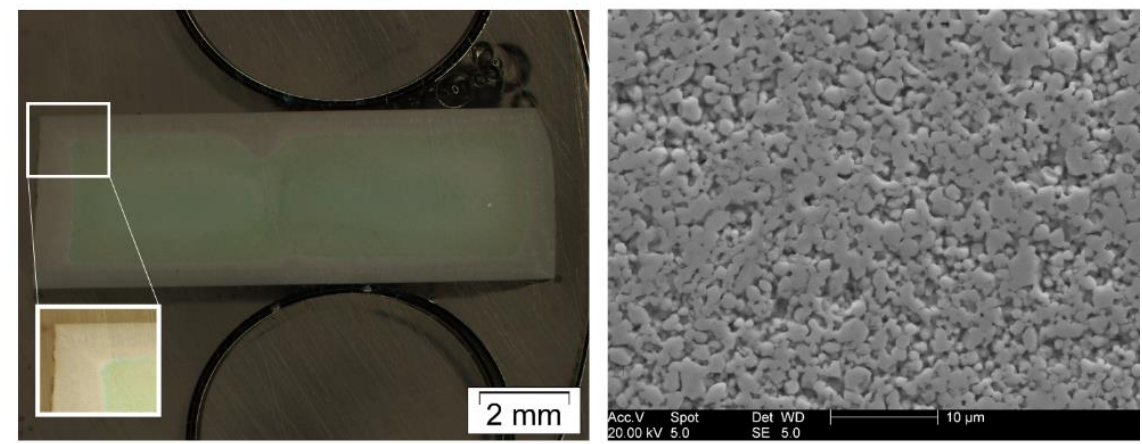

B)
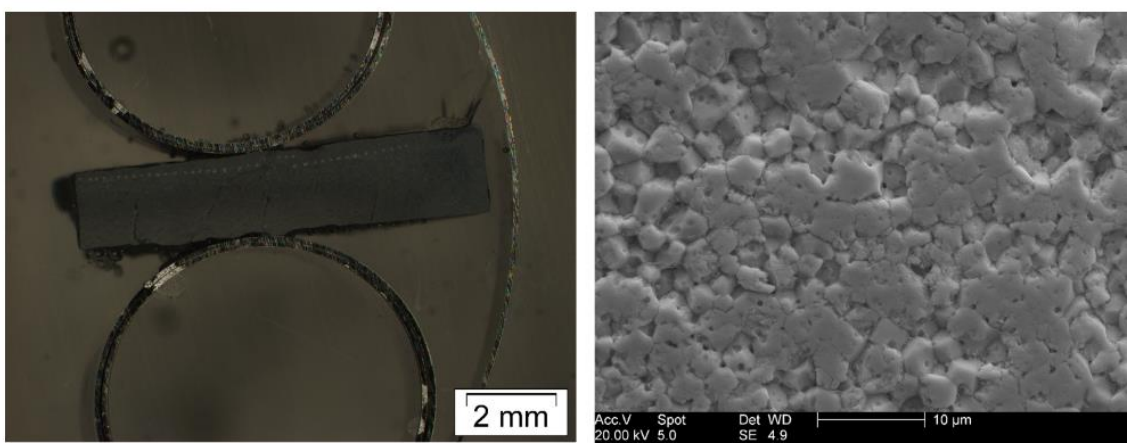

Figure 8: An optical image and SEM image of the microstructure of A) disc A and B) disc B, respectively. The top left corner of disc $A$ is shown with an increased image contrast and brightness to aid the identification of the border region. The green and yellow colouration is an effect caused by absorption of the polishing fluid. 
Relatively intact pellets were made by spark plasma sintering lath-shaped $\mathrm{CeO}_{2}$ powders 1 and 2 (see Table 1) using sintering condition $\mathrm{C}$ (see Figure 2). These will be referred to as SPS pellets $\mathrm{C} 1$ and $\mathrm{C} 2$, respectively ( $C$ refers to sintering condition $\mathrm{C}$ and the numbers refer to the $\mathrm{CeO}_{2}$ batch numbers). These structures had uneven surfaces particularly near the edges as shown in Figure 9. In addition, the edges showed signs of fragmentation. These were all observed on removal from the SPS die except for the large exposed area shown in pellet $\mathrm{C} 2$ that was produced by a spontaneous fracture a week after SPS. The pellets were dark grey immediately after sintering but gradually changed back to a beige colour. This is shown in the fragmented regions in Figure 9. This occurred despite efforts to store the samples in thermally sealed bags with the air expelled, which were packed in another bag with desiccant inside to minimise water absorption. The relative densities of pellets $\mathrm{C} 1$ and $\mathrm{C} 2$ were $85 \pm 0.5 \%$ and $84 \pm 0.5 \%$, respectively. Approximately 3.5 months after sintering, the pellets were removed from their vacuum packs. The samples fragmented and those associated with pellet $\mathrm{C} 2$ are shown in Figure 10. The fragments showed signs of colour change to beige. A significant portion of the SPS pellet C2 had turned beige with the central region still dark grey as illustrated in Figure 10. The pellet could not be sectioned lengthways or in cross-section due to insufficient handling strength. A fragment of the original pellet was cold mounted in epoxy resin, ground and polished (see Figure 11). As the sample was ground, more of the beige material was removed and dark grey regions became more visible with some evidence of cracking.

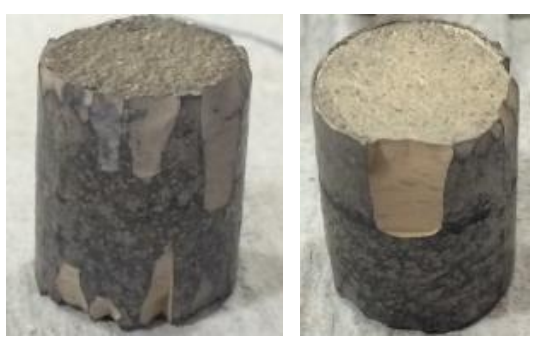

Figure 9: Images of the pellets (a) C1 and (b) C2 (nominally $\varnothing 13 \mathrm{~mm} \times 16 \mathrm{~mm}$ ) 1 week after SPS.

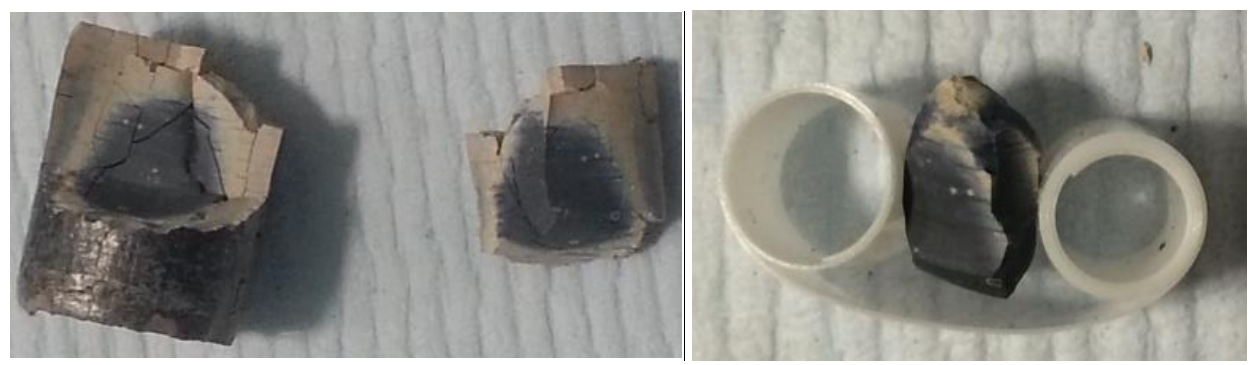

Figure 10: Two major fragments (left) of SPS pellet C2 approximately 3.5 months after manufacture, where the smaller fragment further broke up to a leave smaller piece (right, shown at higher magnification). 


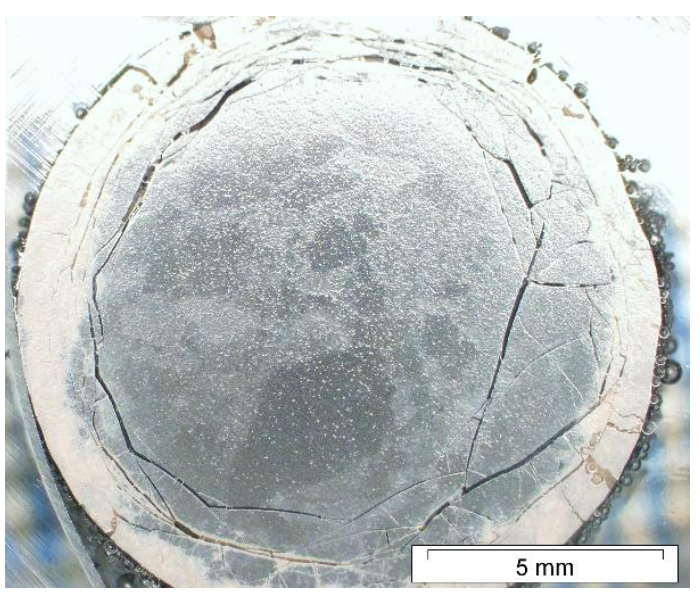

Figure 11: The polished surface of SPS pellet C2.

\subsubsection{Vickers Hardness of SPS $\mathrm{CeO}_{2}$}

For disc A, ten indents that were made using a Mitutoyo MVK-G1 Hardness Tester were analysed using SEM and all were acceptable on the basis of morphology alone (per ASTM C1327-08 [31]). Indent dimensions were measured twice per indent to account for operator variability, which resulted in two sets of hardness measurements for the sample. The mean Vickers hardness with its standard deviation is shown in Table 3. The mean hardness values were very similar for the two measurement sets (2.7 GPa cf $2.8 \mathrm{GPa}$ ), which are combined into a single mean in Table 3.

On disc $B$, indent morphology was affected by the extensive pull-out on the surface caused during grinding and polishing, as shown in Figure 8. This pull-out was consistent with Figure 7, which showed the grains in the fractured surface were not well consolidated. There is an element of subjectivity in assessing the acceptability of indents. In this case, they were judged not to be acceptable, and so no Vickers hardness values are reported for disc B in Table 3.

The near-net shaped pellet $\mathrm{C} 2$, which was manufactured using lath-shaped $\mathrm{CeO}_{2}$, did not yield a sufficient number of acceptable indentations to allow a hardness value to be determined. The indentations had large amounts of grain displacement around them. The low resistance to indentation of this material was not unexpected given that the pellet had fragmented prior to cold mounting. 
Table 3: Comparison of Vickers hardness measurements.

\begin{tabular}{|c|c|c|c|c|}
\hline Material & $\begin{array}{l}\text { Sintering Technique/ } \\
\text { Profile }\end{array}$ & Disc & $\begin{array}{l}\text { Vickers } \\
\text { Hardness } \\
\text { (GPa) }\end{array}$ & $\begin{array}{l}\text { Standard } \\
\text { Deviation (GPa) }\end{array}$ \\
\hline $\mathrm{CeO}_{2}$ & $\begin{array}{l}\text { Spark Plasma Sintering/ } \\
\text { Condition A; see Figure } 2 .\end{array}$ & A & 2.7 & 0.32 \\
\hline \multirow[t]{4}{*}{$\mathrm{CeO}_{2}$} & $\begin{array}{l}\text { Cold-Pressing-and- } \\
\text { Sintering; see Figure } 3 .\end{array}$ & 1 & 5.7 & 0.40 \\
\hline & & 2 & 5.5 & 0.26 \\
\hline & & 3 & 5.7 & 0.20 \\
\hline & & 5 & 6.4 & 0.25 \\
\hline $\mathrm{Nd}_{2} \mathrm{O}_{3}$ & $1350^{\circ} \mathrm{C} / 50 \mathrm{MPa} / 3 \mathrm{~min}$ & $\begin{array}{l}20 \mathrm{~mm} \\
\text { disc }\end{array}$ & 1.08 & 0.01 \\
\hline
\end{tabular}

\subsubsection{Cold-Press-and-Sinter Behaviour of Lath-shaped $\mathrm{CeO}_{2}$}

The powder particle properties of the input $\mathrm{CeO}_{2}$ impacted the green disc handling strength to the extent that some powders could not be pressed successfully (batches 4 and 6 described in Table 1 ). Batches 1, 2, 3 and 5 were cold-pressed-and-sintered successfully and the dimensions and geometric densities are given in Table 4. The results show that the particle properties impact the sintered disc relative density. Discs 2 and 5 delaminated into three and two layers, respectively.

Table 4: Successful cold-press-and-sinter $\mathrm{CeO}_{2}$ trials

\begin{tabular}{llllll}
\hline Batch \# & $\begin{array}{l}\text { Green Disc } \\
\text { Thickness }(\mathrm{mm})\end{array}$ & $\begin{array}{l}\text { Sintered } \\
\text { Thickness }(\mathrm{mm})\end{array}$ & $\begin{array}{l}\text { Sintered } \\
\text { Diameter }(\mathrm{mm})\end{array}$ & Mass $(\mathbf{g})$ & $\begin{array}{l}\text { \% Theoretical } \\
\text { Density }\end{array}$ \\
\hline 1 & 2.21 & 2.10 & 6.78 & 0.4144 & $77 \pm 10$ \\
2 & 2.01 & 1.90 & 6.99 & 0.4403 & $85 \pm 12$ \\
3 & 1.80 & 1.70 & 7.39 & 0.4363 & $83 \pm 12$ \\
5 & 1.83 & 1.80 & 7.01 & 0.3890 & $79 \pm 12$ \\
\hline
\end{tabular}

\subsubsection{Vickers Hardness of Lath-shaped $\mathrm{CeO}_{2}$}

The mounted and polished intact discs are shown in Figure 12. Vickers hardness tests were carried out using a Buehler 1600-6300 Vickers hardness tester in the numbered regions shown in Figure 12. 
SEM analysis was not required as the indents could be analysed optically with the indents in focus. The dark areas were regions infused with resin where specimen cracks were present. The average Vickers hardness values are outlined in Table 3.

The mean hardness values in Table 3 indicate that disc 5 was harder than disc 1, 2 and 3 . The particle properties of the input material affected the Vickers hardness of the sintered body. Student's t-tests were conducted to separately compare the Vickers hardness data for discs 5 and 1, 5 and 2, and, finally, discs 5 and 3. Each of the three tests rejected the null hypothesis that mean Vickers hardness values of the two discs were the same to a confidence of greater than $95 \%$. Thus, the difference in the means are statistically significantly different in each case.
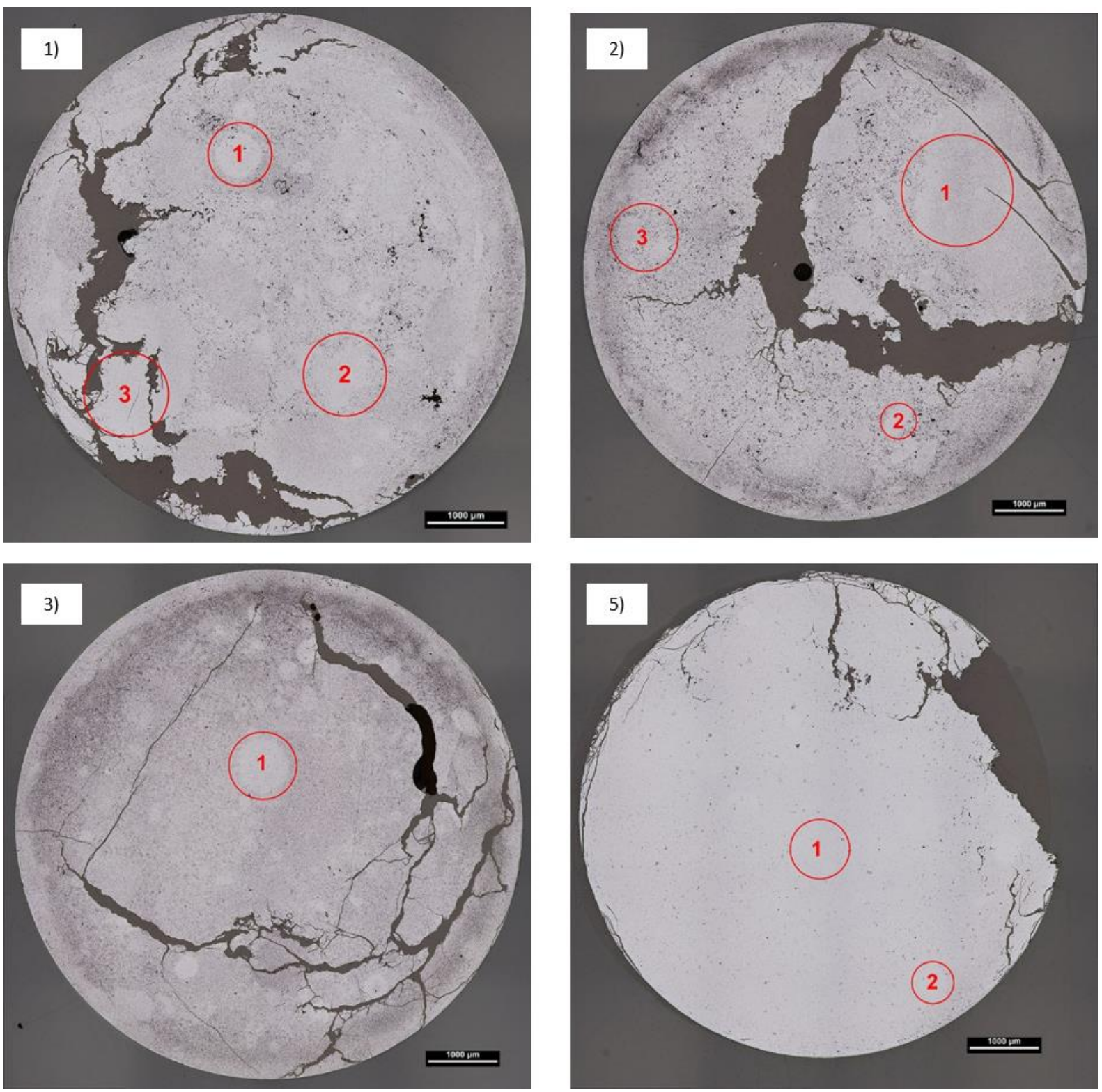

Figure 12: The polished surfaces of discs 1, 2, 3 and 5 cold-pressed-and-sintered discs ( $1 \mathrm{~cm}$ scale bars). Vickers hardness tests were conducted in the numbered regions. 


\subsection{Neodymium (III) Oxide}

\subsubsection{Demonstrating SPS of a Near-Net Shaped Pellet}

Figure 13 illustrates the pellet sintered using commercial $\mathrm{Nd}_{2} \mathrm{O}_{3}$ and sintering profile $\mathrm{C}$. It was intact and had a relative density of $98 \%$. Figure 13 shows that like the $\mathrm{CeO}_{2}$ pellets, the SPS of $\mathrm{Nd}_{2} \mathrm{O}_{3}$ did not result in perfect cylinders; they had material absent near the circular faces.
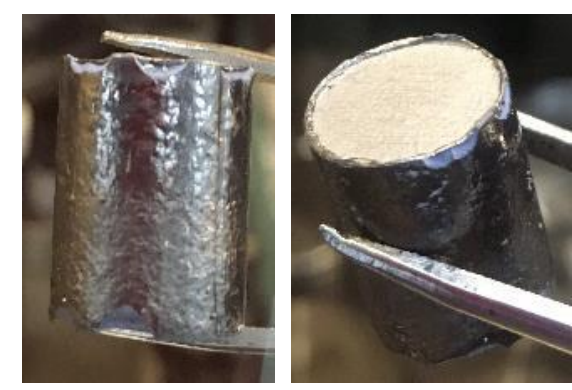

Figure 13: The SPS $\mathrm{Nd}_{2} \mathrm{O}_{3}$ pellet (nominally $\varnothing 13 \mathrm{~mm} \times 16 \mathrm{~mm}$ ) sintered using Condition C (see Figure 2).

\subsubsection{Sintering to a Target Relative Density Range}

Figure 14 illustrates the relative densities of the discs with $20 \mathrm{~mm}$ nominal diameter sintered at different temperatures. To achieve a target relative density of 85-90 \%, a near-net shaped pellet was sintered at $1080^{\circ} \mathrm{C}$. This pellet suffered some local edge fragmentation in a similar matter to the $\mathrm{CeO}_{2}$ pellets manufactured by SPS as shown in Figure 9. The density of the resulting $\mathrm{Nd}_{2} \mathrm{O}_{3}$ pellet is also shown in Figure 14, and has a notably higher relative density ( $94 \%$ ) than predicted by the trend of the curve produced by sintering $20 \mathrm{~mm}$ diameters discs. 


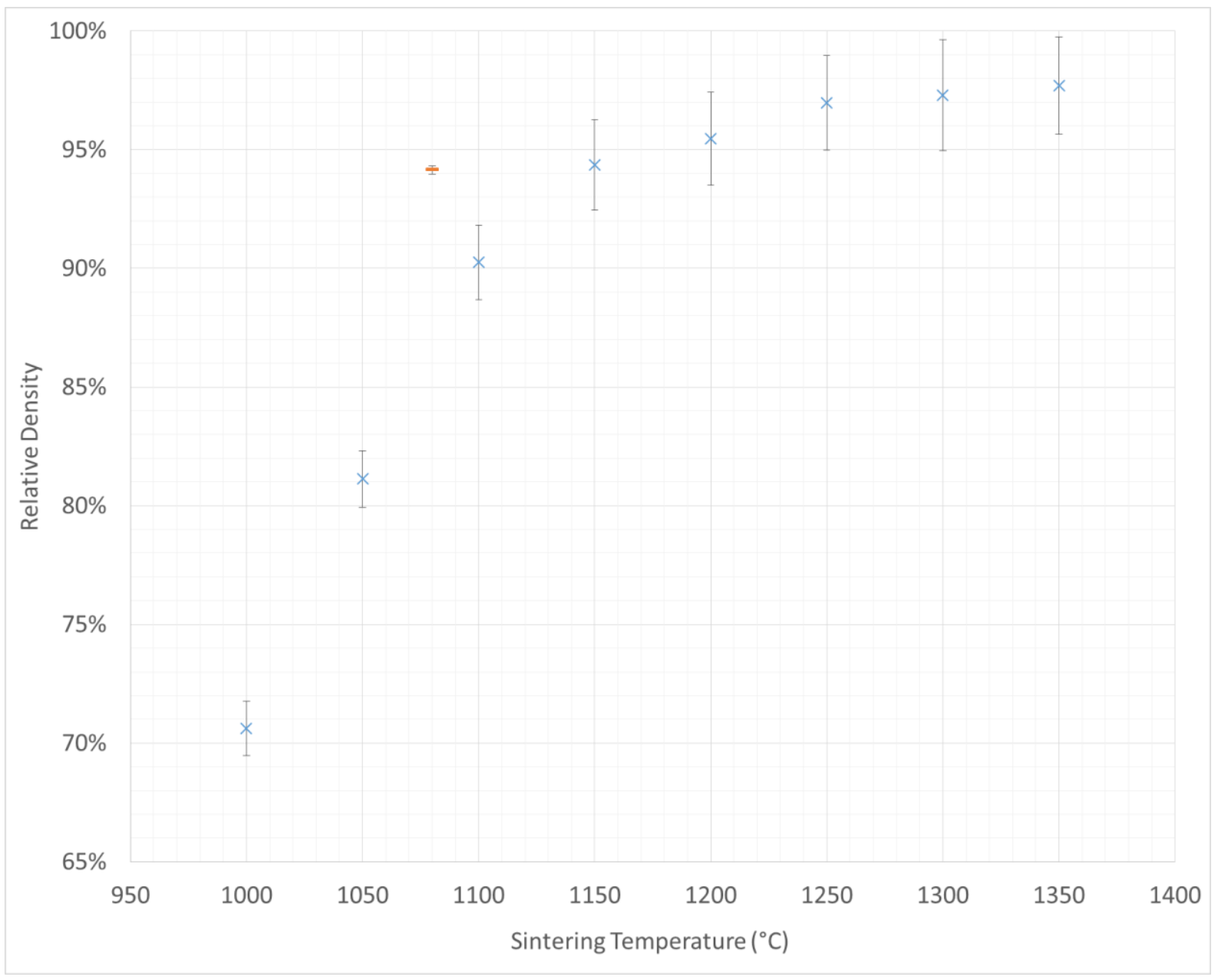

Figure 14: Illustrates the relative density versus sintering temperature results for the $\varnothing 20 \mathrm{~mm} \mathrm{Nd}_{2} \mathrm{O}_{3}$ discs (blue crosses) and for the near-net shaped pellet (orange rectangle).

\subsubsection{Vickers Hardness of $\mathrm{Nd}_{2} \mathrm{O}_{3}$}

Vickers hardness tests were conducted on the $1350{ }^{\circ} \mathrm{C}$ disc from Figure 14 . This disc was selected in an attempt to generate a bounding maximum Vickers hardness (it was sintered to the highest density) value for $\mathrm{Nd}_{2} \mathrm{O}_{3}$ and to maximise the chance of generating acceptable indents. Unlike with the spark plasma sintered $\mathrm{CeO}_{2}$, the acceptability of the Vickers indents could be made with the optical microscope of the hardness test machine. Ten out of eleven indents were deemed acceptable. The Vickers hardness is reported in Table 3, which shows that the value was notably lower than $\mathrm{CeO}_{2}$.

\section{Discussion}

\section{1 $\mathrm{CeO}_{2}$}

\subsubsection{Spark Plasma Sintering Commercially Sourced and Lath-shaped $\mathrm{CeO}_{2}$}

Spark plasma sintering with graphite is known to provide a reducing environment. Nearly all the spark plasma sintered $\mathrm{CeO}_{2}$ discs or pellets were grey, which was consistent with the observations made by Bevan [32] for $\mathrm{CeO}_{2-x}$. Knachel et al. [33] investigated the reduction behaviour of $\mathrm{CeO}_{2}$ and 
produced samples with differing shades of grey or blue. They found that direct physical contact with graphite was not needed to cause the reduction. Thus, according to these pieces of literature, the grey appearance of the spark plasma sintered discs and pellets was indicative of the partial reduction of $\mathrm{CeO}_{2}$. An example of sample outgassing during SPS was shown in Figure 6 for a disc fabricated using a one-stage process. The only sources for gas production would have been oxygen from the sample or the carbon monoxide or dioxide as a consequence of the reaction with the graphite die. It is likely that reduction of the $\mathrm{CeO}_{2}$ as described by Zhou et al. [17] occurred during the experiment. Zhou et al. [17] attributed the observed weight loss in their $\mathrm{CeO}_{2}$ powders to the reduction of the source material to $\mathrm{Ce}_{2} \mathrm{O}_{3}$. They state that the loss was particularly large beyond $1200{ }^{\circ} \mathrm{C}$. The data presented in Figure 6 are in agreement.

Although an increase in temperature resulted in an increase in density for one-stage SPS, it was difficult to produce intact discs. A small change in SPS parameters resulted in a large change in disc density and in fracture surface microstructure. This was evidenced by both the one-stage and twostage sintering trials. $\mathrm{CeO}_{2}$ densification is thus difficult to control when using SPS. The 2-stage sintering profiles (condition A and B) were thought to have successfully produced intact $20 \mathrm{~mm}$ discs by permitting outgassing prior to densification. Although disc $A$ was intact, the relative density was too low for the sintering conditions to be used further. The breakage in disc $B$ whilst being removed from the die highlights that the handling strength of the material produced is still a concern.

On initial inspection, relatively intact pellets with relative densities in the mid-80 \% were made using SPS when the particle properties of the input $\mathrm{CeO}_{2}$ was changed from sub $5-\mu \mathrm{m}$ agglomerates to larger lath-shaped particles, which were produced using the wet chemical process proposed for fuel manufacture. Both pellets $\mathrm{C} 1$ and $\mathrm{C} 2$ were not perfectly cylindrical due to edge fragmentation. Thus SPS could not achieve the desired geometry and appears unlikely to be able to do so with reproducibility.

The colour change in the SPS pellets (sintered using synthesised lath-shaped $\mathrm{CeO}_{2}$ ) to dark grey and back to beige suggested reduction and re-oxidation, respectively. The suspected changes in oxygen to metal ratio and the irregular edges of the compacts would have added some uncertainty to the density measurements. The fragmentation following storage suggested the handling strength had diminished significantly. It is likely this oxidation is a factor in the fragmentation observed. Given that $\mathrm{AmO}_{2}$ has a greater tendency to reduce [34], the complexity in spark plasma sintering $\mathrm{AmO}_{2}$ is likely to be even greater.

\subsubsection{Cold-Pressing-and-Sintering Lath-shaped $\mathrm{CeO}_{2}$ with Varying Particle Sizes and Specific Surfaces Areas}

Some of the cold-pressed-and-sintered ceria discs suffered from unwanted delamination. Americium oxide particles made via the oxalate precipitation and calcination route have similar lath morphologies; if the $\mathrm{CeO}_{2}$ cold-press-and-sinter behaviour is indicative of $\mathrm{AmO}_{2}$, then methods into preventing delamination may need to be investigated.

The physical characteristics of the $\mathrm{CeO}_{2}$ starting powder plays an important role in being able to press integral discs. Batch 3 pressed particularly well. However, the inability to press batch 4 and yet to be able to press batch 1 is unexpected as they had similar specific surface areas and particle size distributions (apart from $d_{90}$ values) according to Table 1 . The green strengths of the intact discs were not measured but their integrities were qualitatively assessed as adequate. Discs 2 had a relative densities that met the target of $85-90 \%$, but disc 5 had a lower density (see Table 4). The 
Vickers hardness of disc 5 was greater than that of disc 2 . Table 1 shows that the powder in batch 5 had a similar specific surface area to batch 2 , but the estimated particle sizes were notably lower in batch 5 . These data show no evidence of the nature of the relationship between particle size, specific surface area, sintering behaviour and hardness. They do indicate that changes to the production parameters of the powder have a significant impact on final properties for this material. From this, it must be assumed that the situation will be similarly complex for americium oxide compounds.

\subsubsection{Vickers Hardness Comparison of Spark Plasma Sintered and Cold-Pressed-and-Sintered $\mathrm{CeO}_{2}$}

Vickers hardness does not provide a direct indication of mechanical properties other than resistance to indentation. However, it provides an initial indication and means of comparison of the mechanical properties of these sintered $\mathrm{CeO}_{2}$ discs and pellets. The processes necessary to prepare the specimen and generate valid hardness data do give an indication of potential practical issues with handling the material. Vickers hardness tests of the 2-stage spark plasma sintered $\operatorname{discs} A$ and $B$ and pellet $C 2$ indicated generally low resistance to indentation, with acceptable idents only achieved in disc A. The inability to obtain valid hardness data from an SPS pellet produced using lath-shaped $\mathrm{CeO}_{2}$ particles indicates a potential concern for the use of this material (and $\mathrm{AmO}_{2}$ ) and identifies an area for future work. Disc A had a much lower Vickers hardness than the cold-pressed-and-sintered discs (see Table 3). This again suggests inferior mechanical performance, perhaps attributable to the greater reduction during the sintering process disrupting the microstructure. A comparison of the measured Vickers hardness data in this study cannot be made with $\mathrm{AmO}_{2}$ or $\mathrm{Am}_{2} \mathrm{O}_{3}$ due to the lack of published data. The mechanical properties of $\mathrm{UO}_{2}$ are used as a reference for a nuclear material. The Vickers hardness of disc A was much lower than that of $\mathrm{UO}_{2}(5.88 \mathrm{GPa})$ [35], whereas the coldpressed-and-sintered discs and pellets had hardness values that were consistent with $\mathrm{UO}_{2}$. This indicated their resistance to indentation was comparable to a nuclear material.

\subsection{Spark Plasma Sintering $\mathrm{Nd}_{2} \mathrm{O}_{3}$}

\subsubsection{Initial Pellet Fabrication}

It was demonstrated that a high relative density and intact $\mathrm{Nd}_{2} \mathrm{O}_{3}$ pellet can be produced by SPS. This was thought to be because $\mathrm{Nd}_{2} \mathrm{O}_{3}$ does not reduce as readily as $\mathrm{CeO}_{2}$ as it is already in a lower oxidation state [36]. The sintering condition profile $\mathrm{C}$ (see $\S 3.2$ ) resulted in a $98 \%$ relative density. However, an $\mathrm{Am}_{2} \mathrm{O}_{3}$ pellet may not have the capacity to allow helium outgassing if $\mathrm{Am}_{2} \mathrm{O}_{3}$ were to behave like $\mathrm{Nd}_{2} \mathrm{O}_{3}$ under SPS i.e. to sinter to such a high density.

\subsubsection{Demonstrating the Target Relative Density}

Figure 14 illustrates that $20 \mathrm{~mm}$ diameter discs can be fabricated with relative densities of over $95 \%$ at temperatures as low as $1200^{\circ} \mathrm{C}$. The disc sintered at $1350{ }^{\circ} \mathrm{C}$ had a comparable relative density to the pellet sintered using sintering profile $\mathrm{C}$ (Figure 2 ) despite the difference in aspect ratio and pressure. Although the near-net shaped pellet sintered at $1080^{\circ} \mathrm{C}$ was expected to have a relative density within the target range (85-90\%) according to Figure 14 , its relative density was much higher than expected at $94 \pm 0.2 \%$. The change in aspect ratio may have impacted the densification process. Future investigations need to be conducted to establish how target densities can be achieved for different ratios, particularly for a near-net shaped pellet geometry. More generally, the data present a clear drive for future studies of the sintering of these materials to use realistic aspect ratios in spite of the large volumes of material required. 
The Vickers hardness value was much lower than the sintered $\mathrm{CeO}_{2}$ (SPS and cold-pressed-andsintered) discs for which acceptable data could be collected (see Table 3). Thus ceria can be spark plasma sintered or cold-pressed-and-sintered to have superior hardness to spark plasma sintered $\mathrm{Nd}_{2} \mathrm{O}_{3}$. This is the first report of the hardness of $\mathrm{Nd}_{2} \mathrm{O}_{3}$ in the literature. Vickers hardness in ceramics is not a direct measurement of mechanical properties, and so the data only support the conclusion that there may be a concern about whether the handling integrity of $\mathrm{Nd}_{2} \mathrm{O}_{3}$ pellets is sufficient to make it an appropriate mechanical surrogate for americium oxide fuels.

\section{Conclusions}

Both the spark plasma sintering and cold-press-and-sinter techniques were able to sinter micrometric $\mathrm{CeO}_{2}$ discs or pellets with relative densities within the target range of 85-90\% without ball-milling the surrogate fuel. Despite this, it has been shown that SPS is an unsuitable method to sinter $\mathrm{CeO}_{2}$ due to the effects of reduction of the material. Intact high density discs could not be produced using commercial material and although relatively intact pellets could be made using larger lath-shaped particles (on initial inspection), the pellets exhibited chipping (initial evidence of fragmentation) and eventual further fragmentation. The study suggests that SPS cannot enable pellets to be made with reproducible geometries without further development. Further to this, as the $\mathrm{CeO}_{2}$ pellets eventually disintegrated into fragments, which indicated that the current method cannot make pellets with stable integrity. Although this may have been caused by gradual oxidation, and the effect of annealing pellets post-SPS could be explored, this will not address the nonreproducible geometry. The design of pellet containment layers in the RPS system will require the reduction extent, crystallographic phase changes and thermal expansion to be characterised. Future $\mathrm{X}$-ray diffraction studies will be conducted to assess the $\mathrm{CeO}_{2}$ reduction behaviour.

Although cold-press-and-sinter takes longer than SPS it has enabled intact $\mathrm{CeO}_{2}$ discs to be made with near-target densities and with higher Vickers hardness. All cold-pressed-and-sintered discs had comparable Vickers hardness to current nuclear ceramics (represented by uranium dioxide, $\mathrm{UO}_{2}$ ), whereas the only meaningful value for the SPS discs was much lower. However, discs manufactured from lath-shaped material by cold-press-and-sinter did exhibit delamination. Furthermore, the effects of differences in particle size and specific surface area of the raw material were found to be significant without it being possible to correlate these effects in this study. Future studies must therefore fully characterise the effects of differences in lath-shaped particle size and specific surface area with the aim of creating a reproducible and well-characterised surrogate fuel form. It is important to note that $\mathrm{AmO}_{2}$ produced via an oxalate precipitation and calcination route has similar lath-shaped morphology and the same considerations may apply.

High-density intact $\mathrm{Nd}_{2} \mathrm{O}_{3}$ discs were successfully produced via SPS, along with the capability to tailor the density in the required range by adjusting the sintering parameters. Using a modified sintering profile for a near-net shape pellet yielded an average density of $94 \pm 0.2 \%$ with some surface fragmentation. This illustrates that the aspect ratio of the pellet does affect the sintering parameters and behaviour. Future work on these materials must focus on representative geometries.

Neodymium (III) oxide may be a suitable mechanical surrogate for $\mathrm{Am}_{2} \mathrm{O}_{3}$; however, the mean Vickers hardness, which was obtained from a limited data set, was much lower than for typical nuclear ceramics. This work requires extension to consider the use of cold-press and sinter, and the effect of raw powder obtained from a wet chemical process.

Cerium and neodymium oxides represent potential mechanical surrogates for the americium oxide fuel under development for the ESA space radioisotope power systems. On the basis of the current 
studies, cold-press-and-sinter has fewer potential complications with reduction. Future research must consider the full effect of the wet-chemical processing parameters on particle characteristics and sintering behaviour in realistic pellet geometries.

\section{Acknowledgements}

The authors would like to acknowledge the funding provided by the Science and Technologies Facilities Council [ST/K/502121/1] and the European Space Agency [TEC-EPS/2009/531, E903001EP]. The work carried out in collaboration with the University of Dayton Research Institute is part of the Implementing Arrangement between the University of Dayton and the University of Leicester. The authors would like to acknowledge the advice and assistant provided by V. Patel and G. Clark from the Department of Engineering (University of Leicester) for SPS disc/pellet mounting.

\section{References}

1. G. L. Bennett, Space Nuclear Power: Opening the Final Frontier, in 4th International Energy Conversion Engineering Conference and Exhibit (IECEC) \#AIAA 2006-4191. 2006, American Institute of Aeronautics and Astronautics: San Diego, California, USA.

2. Idaho National Laboratory Batelle Energy Alliance, LLC, Space Nuclear and Isotope Technologies Division, Atomic Power in Space II, INL/EXT-15-34409, 2015.

3. R. G. Lange and W. Caroll et al., Review of Recent Advances of Radioisotope Power Systems, Energy Convers. Manage, 2008. 49: p. 393-401. http://dx.doi.org/10.1016/j.enconman.2007.10.028

4. L. Summerer and K. Stephenson, Nuclear Power Sources: a Key Enabling Technology for Planetary Exploration, Proc. IMechE G: J. Aero. Eng., 2011. 225: p. 129-143. http://dx.doi.org/10.1243/09544100JAERO766

5. R. M. Ambrosi et al., Development and Testing of Americium-241 Radioisotope Thermoelectric Generator: Concept Designs and Breadboard System, in: Proc. Nuclear and Emerging Technologies for Space. 2012: The Woodlands, Texas.

6. H. R. Williams et al., A conceptual spacecraft radioisotope thermoelectric and heating unit (RTHU). Int. J. Energy Res., 2012. 36(12): p. 1192-1200. http://dx.doi.org/ 10.1002/er.1864.

7. H. R. Williams et al., Metal Matrix Composite Fuel for Space Radioisotope Energy Sources. J. Nucl. Mater., 2013. 433(1-3): p. 116-123. http://dx.doi.org/10.1016/j.jnucmat.2012.09.030.

8. R. C. O'Brien et al., Safe radioisotope thermoelectric generators and heat sources for space applications. J. Nucl. Mater., 2008. 377(3): p. 506-521. http://dx.doi.org/10.1016/j.jnucmat.2008.04.009

9. M. Borland et al., An Evaluation of Alternate Production Methods for Pu-238 General Purpose Heat Source Pellets \#203585, in: Proc. of Nuclear and Emerging Technologies for Space. 2009: Atlanta, GA, USA.

10. B. Basu et al., Advanced Structural Ceramics. 2011, Hoboken, NJ, USA: John Wiley \& Sons, Inc.

11. R. Aalund, Unveiling Spark Plasma Sintering High-Throughput Processing, in: J.P.S. N. P. Bansal, J. Lamon, S. R. Choi and M. M. Mahmoud (Eds.), Processing and Properties of Advanced Ceramics and Composites II, 2010, John Wiley \& Sons, Inc., Hoboken, NJ, USA. p. 3-10.

12. O. Guillon et al., Field-Assisted Sintering Technology/Spark Plasma Sintering: Mechanisms, Materials, and Technology Developments. Adv. Eng. Mater., 2014. 16(7): p. 830-849. http:/doi.org/10.1002/adem.201300409

13. E. J. Watkinson et al., Cerium neodymium oxide solid solution synthesis as a potential analogue for substoichiometric $\mathrm{AmO}_{2}$ for radioisotope power systems. J. Nuc. Mater., 2017. 486: p. 308322. http://dx.doi.org/10.1016/j.jnucmat.2017.01.011 
14. L. Claparède et al., Influence of Crystallization State and Microstructure on the Chemical Durability of Cerium-Neodymium Mixed Oxides. Inorg. Chem., 2011. 50(18): p. 9059-72. http://dx.doi.org/10.1021/ic201269c

15. M. J. Sarsfield et al., The Separation of 241am from Aged Plutonium Dioxide for Use in Radioisotope Power Systems \#1030, in: European Space Power Conference. 2016: Thessaloniki, Greece.

16. M. J. Sarsfield et al., Sintering and Characterisation of Cerium Dioxide as a Surrogate for Americium-241 \#6079, in: Nuclear and Emerging Technologies for Space 2016. 2016: Hunstville, AL, USA.

17. Y. Zhou and M. N. Rahaman, Effect of Redox Reaction on the Sintering Behaviour of Cerium Oxide. Acta Mater., 1997. 45(9): p. 3635-3639. http://doi.org/10.1016/S1359-6454(97)00052-9.

18. M. Ozawa, Effect of oxygen release on the sintering of fine $\mathrm{CeO}_{2}$ powder at low temperature. Scri. Mater., 2004. 50(1): p. 61-64. http://doi.org/10.1016/j.scriptamat.2003.09.040

19. Y. Wang, Effect of Reduction Treatment on Microstructure and Mechanical Properties of Fluorite Oxides. 2006, PhD Thesis, University of Florida.

20. J. G. Li et al., Characterization and sintering of nanocrystalline $\mathrm{CeO}_{2}$ powders synthesized by a mimic alkoxide method. Acta Mater., 2001. 49(3): p. 419-426. http://doi.org/10.1016/S13596454(00)00327-X

21. Y. C. Zhou et al., Hydrothermal synthesis and sintering of ultrafine $\mathrm{CeO}_{2}$ powders. J. Mater. Res., 1993. 8(7): p. 1680-1686. http://doi.org/10.1557/JMR.1993.1680

22. M. T. Jahromi, Synthesis, Kinetics and Sintering Studies of Nano/Micro $\mathrm{CeO}_{2}$ Powder (Masters Thesis), in School of Mechanical and Aerospace Engineering. 2009, Nanyang Technological University.

23. S. Meriani, Features of the Caeria-Zirconia systems. Mater. Sci. Eng. A, 1989. 109(C): p. 121-130. http://doi.org/10.1016/0921-5093(89)90575-3

24. J. Roleček et al., A feasibility study of using $\mathrm{CeO}_{2}$ as a surrogate material during the investigation of $\mathrm{UO}_{2}$ thermal conductivity enhancement. Adv. App. Ceram., 2017: p. 1-9.

http://doi.org/10.1080/17436753.2016.1264122

25. J. M. Heintz et al., Sintering of $\mathrm{Nd}_{2} \mathrm{O}_{3}$ and Ceramic Stability to Hydration, in: L.-C. Dufour et al. (Eds.), Surfaces and Interfaces of Ceramic Materials, 1989, Springer Netherlands: Dordrecht. $p$ 565-574.

26. K. Choi et al., Densification of $\mathrm{Nano}-\mathrm{CeO}_{2}$ Ceramics as Nuclear Oxide Surrogate by Spark Plasma Sintering. J. Nucl. Mater., 2010. 404(3): p. 210-216. http://dx.doi.org/10.1016/j.jnucmat.2010.07.018

27. K. Choi et al., Effect of Dysprosia Additive on the Consolidation of $\mathrm{CeO}_{2}$ by Spark Plasma Sintering. J. Am. Ceram. Soc., 2012. 95(5): p. 1524-1529. http://doi.org/10.1111/j.15512916.2011.05054.x

28. T. Mori et al., Synthesis and Characterization of Nano-Hetero-Structured Dy Doped CeO2 Solid Electrolytes Using a Combination of Spark Plasma Sintering and Conventional Sintering. J. Am. Ceram. Soc., 2005. 88(7): p. 1981-1984. http:doi.org/10.1111/j.1551-2916.2005.00260.x

29. H. Muta et al., Thermophysical properties of $\mathrm{Th}_{1-\mathrm{x}} \mathrm{U}_{\mathrm{x}} \mathrm{O}_{2}$ pellets prepared by spark plasma sintering technique. J. Nuc. Sci. Technol., 2013. 50(2): p. 181-187. http://doi.org/10.1080/00223131.2013.757468

30. L. Ge et al., Densification of uranium dioxide fuel pellets prepared by spark plasma sintering (SPS). J. Nuc. Mater., 2013. 435(1-3): p. 1-9. http://doi.org/10.1016/j.jnucmat.2012.12.010 
31. ASTM C1327 - 08, Standard Test Method for Vickers Indentation Hardness of Advanced Ceramics. 2008: ASTM International, PA, USA.

32. D. J. M. Bevan, Ordered Intermediate Phases in the System $\mathrm{CeO}_{2}-\mathrm{Ce}_{2} \mathrm{O}_{3}$. J. Inorg. Nucl. Chem., 1955. 1(1-2): p. 49-59. http://dx.doi.org/10.1016/0022-1902(55)80067-X

33. $\mathrm{H}$. Knachel et al., Reduction of $\mathrm{CeO}_{2}$, a $\mathrm{PuO}_{2}$ Surrogate, via Gas Phase Interaction with Graphite, in: Nuclear and Emerging Technologies for Space. 2015: Albuquerque, NM, USA

34. C. E. Whiting et al., Modeling the Substoichiometric Behavior of ${ }^{238} \mathrm{PuO}_{2}$ and ${ }^{241} \mathrm{AmO}_{2}$ in the Low Oxygen Potential Environments Found in Radioisotope Power Systems. in: Nuclear and Emerging Technologies for Space. 2015 Albuquerque, NM, USA.

35. F. Cardarelli, Ceramics, Refractories, and Glasses, in Materials Handbook: A Concise Desktop Reference. 2008, Springer London: London. p. 593-689.

36. M. Arin et al., Effect of Different Stabilizer Addition on Preparation and Hydrothermal Stability of $\mathrm{ZrO}_{2}$-Tin Composites with varying Tin Content. Key Eng. Mater., 2008. 361-363: p. 795-798. http://doi.org/10.4028/www.scientific.net/KEM.361-363.795 